\title{
The Effect of Three Different Feed Types on Growth Performance and Survival of African Catfish Fry (Clarias gariepinus) Reared in a Hatchery
}

\author{
Safina M. Musa, ${ }^{1}$ Christopher Mulanda Aura, ${ }^{2,3}$ Charles Chege Ngugi, ${ }^{4}$ and Rodrick Kundu ${ }^{5,6}$ \\ ${ }^{1}$ Kegati Aquaculture Research Station, Kenya Marine and Fisheries Research Institute, P.O. Box 3259-40200, Kisii, Kenya \\ ${ }^{2}$ Kenya Marine and Fisheries Research Institute, P.O. Box 85651-80100, Mombasa, Kenya \\ ${ }^{3}$ Laboratory of Marine Bioresource and Environment Sensing, Hokkaido University, Minato-Cho, Hakodate, \\ Hokkaido 041-8611, Japan \\ ${ }^{4}$ Ministry of Fisheries Development, P.O. Box 58187-00200, Nairobi, Kenya \\ ${ }^{5}$ Ministry of Fisheries Development, P.O. Box 1084-40100, Kisumu, Kenya \\ ${ }^{6}$ Lake Victoria Environmental Management Project Phase II, P.O. Box 9220-40100, Kisumu, Kenya
}

Correspondence should be addressed to Safina M. Musa, safeenamusa@yahoo.com

Received 13 April 2012; Accepted 25 June 2012

Academic Editors: D. V. Andrade and B. A. Young

Copyright (C 2012 Safina M. Musa et al. This is an open access article distributed under the Creative Commons Attribution License, which permits unrestricted use, distribution, and reproduction in any medium, provided the original work is properly cited.

\begin{abstract}
African catfish Clarias gariepinus is cultured as food fish, used to control overpopulation in tilapia ponds, and is grown as baitfish for the Lake Victoria Nile Perch fishery. Since the demand for Clarias gariepinus fingerlings is high, many farmers wish to specialize in fingerling production. In this study, the performance of three dietary feed types: freshwater rotifers with Artemia nauplii, freshwater rotifers with fish meal, and freshwater rotifers with maize bran, on the growth performance of African catfish fry, were done in a hatchery and they were raised in 9 glass tanks for a period of 21 days. Pearson's correlation showed no relationship $(r=0.1 ; P>0.05)$ between growth and water quality parameters, but indicated a strong relationship between survival rate and total length between treatments $(r=0.85 ; P=0.02)$. Mean total length $(\mathrm{TL})$ after 21 days were $(\mathrm{A}=15.003),(\mathrm{B}=12.964)$, and $(\mathrm{C}=11.90)$ in $\mathrm{mm}$ for Treatments $\mathrm{A}, \mathrm{B}$, and $\mathrm{C}$, respectively. Treatment $\mathrm{A}$ had the highest specific growth rate (SGR) of $6.475 \%$ day 1 followed by B $\left(5.5320 \%\right.$ day $\left.^{-1}\right)$ and C $\left(4.960 \%\right.$ day $\left.^{-1}\right)$. Results from this study demonstrate that after the 7 days of feeding using rotifers, Artemia is the best feed for increasing growth of Clarias gariepinus.
\end{abstract}

\section{Introduction}

Fish consumption is growing at the rate of $2.4 \%$ p.a. while the human population is increasing at the rate of $2 \%$ p.a. [1]. Thus, the growth of population is outpacing that of fish as food since 1980; creating increasing market demand. This has led to the overexploitation of capture fisheries due to overcapacity and over fishing. Hence, there is need for increased aquaculture production to supplement the capture fisheries and solve the market demand of fish and fish products. The species selected to portray yield potential in Africa for aquaculture production are Nile tilapia
(Oreochromis niloticus), Common carp (Cyprinus carpio), and African catfish (Clarias gariepinus). These species are widely distributed and have already performed well for fish farming in the continent. Under small-scale conditions, African catfish because of its tolerance to crowding produces a critical standing crop of about 21 metric tonnes under commercial farming [1]. An omnivorous scavenger that eats everything it finds, the African catfish is particularly amenable to the farming practices of smallholders, who comprise the majority of farmers in developing countries. It is also favored for controlling tilapia recruitment because it fetches higher market prices than other "police" species. 
However, the persistent lack and/or high price of even small catfish fingerlings in such countries is a major constraint to aquaculture development [2].

The aquaculture potential of Clarias gariepinus in Africa was first realized by Douglas Hey at the Jonkershoek Fish Hatchery in the Western Cape Province in South Africa in 1941. Until the mid-1970s, however, the aquaculture research effort was relatively low key until the publication of two important papers, the one by De Kimpe and Micha [3] and the other by Ritcher [4] that could have triggered more research efforts in aquaculture. Since the mid-1970s, research on African catfish culture has mushroomed and has been undertaken in several laboratories in The Netherlands, South Africa, Belgium, Central African Republic, and Ivory Coast. These largely independent but parallel research initiatives resulted in the rapid development of the technology throughout Africa. For example, in southern Africa, the research and development phase lasted for mere 7 years before the results were translated into commercial practice [5].

African catfish, Clarias gariepinus, from a biological perspective, is undoubtedly the ideal aquaculture species in the world. It is widely distributed, thrives in diverse environments (temperate to tropical), and is hardy, adaptable, and an ecological pioneer species, principally as a major consequence of its air-breathing ability. It feeds on a wide array of natural prey and can adapt its feeding habits depending on food availability. It is able to withstand adverse environmental conditions, and is highly fecund and easily spawned under captive conditions [6]. Nyina-Wamwiza et al. [6] noted that the lack of appropriate feed and presence of predators are more likely causes of mortality or poor and erratic fish survival rates curtailing the need to produce enough fingerlings using the quickest way possible to the high demand of fish in ponds. Hence, there is need to address the issue of faster growth rate performance so as to meet the high demand of fish and to favour high a shorter growth span. Thus, this research aimed at determining the growth performance of three feed types (freshwater rotifers plus Artemia nauplii, freshwater rotifers plus fishmeal, and freshwater rotifers plus maize bran of Clarias gariepinus fry and their survival rates).

\section{Materials and Methods}

The study was conducted at Moi University, Chepkoilel campus, and the specific area was at the Hatchery of the Fisheries and Aquatic Sciences Department (Figure 1). The campus is situated $9 \mathrm{Km}$ northeast of Eldoret Municipality on the Eldoret-Ziwa road. The campus is within Rift valley Province, Uasin Gishu district, Eldoret town. The town occupies a global position of $0^{\circ} 35^{\circ} \mathrm{N}$ and $35^{\circ} \mathrm{N} 12^{\circ} \mathrm{E}$ at an altitude of $2180 \mathrm{M}$ above sea level [7].

Experimental fish (Clarias gariepinus larvae) were obtained by artificial reproduction using the method described by Ngugi et al. [7]. A total of two sexually mature females (each $500 \mathrm{~g}$ ) and four males (each $280 \mathrm{~g}$ ) from Chepkoilel fish farm (Uasin Gishu, Rift Valley province, Kenya) were used. The fish were transported to the hatchery of Chepkoilel Campus, Moi University, where spawning was induced by hypophysation. The two female catfishes were injected with pituitary that was obtained from four of the males. The females were kept in tanks separately at $26^{\circ} \mathrm{C}$ with air stone aerators and were stripped 18 hours after the time of injection. A total weight of about $200 \mathrm{~g}$ of eggs was obtained and then fertilized artificially using milt from the remaining two male catfishes. The fertilized eggs were put in an incubator ( $92 \mathrm{~cm}$ length, $45.5 \mathrm{~cm}$ wide, and $32 \mathrm{~cm}$ in height) on a slanting tray for a period of 24 hours, aerated with air stones and subjected to a temperature of $26^{\circ} \mathrm{C}$. After hatching, the larvae was transferred into a hatchling tank for 3 days until the larvae completely absorbed the yolk sac. The catfish fry were fed on rotifers for 7 days as starter feed to obtain uniform growth length before they were transferred to the 9 experimental tanks to be fed on three different diets (artemia nauplii, fishmeal, and maize bran). Experimental trials were done to check on the efficiency of water monitoring to reduce mortality rate of fry.

Experimental culture units consisted of $40.0 \mathrm{~L}$ glass tanks ( $45.6 \mathrm{~cm}$ in length, $32 \mathrm{~cm}$ wide, and $31 \mathrm{~cm}$ in height). Tanks after being washed with jik and $O M O$, were filled with $30.0 \mathrm{~L}$ of dechlorinated tap water whose temperature was raised to $24^{\circ} \mathrm{C}$. Water in each tank was gently aerated with a single air stone. A total of 9 tanks were each stocked with 50 fish larvae at the start of the experiment. Three dietary types (Artemia nauplii, fishmeal, and maize bran) were assigned to the 9 tanks in a completely random manner. Each treatment had 3 replicates. The experiment lasted for 14 days after stocking.

For the monitoring of water quality, bottom debris was siphoned from each tank twice a day, once before the first reading, and again 30 minutes after the last feeding. Since water loss may occur during siphoning, $0.5-1.0 \mathrm{~L}$ of dechlorinated tap water was added daily to each tank to maintain water volume at $30.0 \mathrm{~L}$. However, after every 7 days, $60 \%$ of the water in each tank was changed. This coincided with the day of sampling for total length (TL), total ammonia-nitrogen (TAN), nitrite-nitrogen, $\mathrm{pH}$, and survival rates. Temperature and dissolve oxygen were measured daily at 9.00 AM and 4.00 PM with a dissolved oxygen meter. Total ammonia-nitrogen (TAN) and nitritenitrogen were monitored in each tank every 7 days during the experiment. $\mathrm{PH}$ was measured and monitored in the experimental tanks using a $\mathrm{pH}$ meter after every 7 days interval during the experimental period.

Three test feeds of Artemia nauplii (Treatment A), fishmeal (Treatment B), and maize bran (Treatment C) were used in this experiment. Rotifers that formed starter feed for 7 days were cultured in a $180 \mathrm{~m}^{2}$ earthen pond located at the Moi University fish farm. The pond was fertilized by chicken manure at the rate of $0.5 \mathrm{kgm}^{-2}$ week $^{-1}$. Rotifers were harvested using 80-micrometer plankton net and fed to catfish fry five times a day at a 2-hour interval (10.00 AM to $6.00 \mathrm{PM}$ ). 180-micrometer plankton net was used to sieve the sample to remove large debris before feeding the fish. Artemia nauplii cysts were hatched in saline water (35 g of common salt in one liter of tap water, or $35 \mathrm{ppt})$. Temperature was maintained at $28^{\circ} \mathrm{C}$ by inserting a thermostat (heater) vertically in to the culture bottle. A total of $2.0 \mathrm{~g}$ of 
cysts were incubated in a $5.0 \mathrm{~L}$ plastic bottle. The water in the incubation bottle was aerated with a single air stone, which maintains dissolved oxygen at or above $5 \mathrm{mg}^{-1}$. The cysts hatched after 20-24 hours of incubation. Before feeding the fish in Treatment A, Artemia nauplii were separated from the floating cyst shells, crashed, and subsequently weaned for the remaining 14 days. The Department of Fisheries and Aquatic Sciences, Moi University provided fishmeal (Treatment B) and maize bran (Treatment C) that were crashed and fed on them for 14 days to satiation, five times a day, at 2-hour intervals at $10.00 \mathrm{AM}$ and ending at 6.00 $\mathrm{PM}$ ad libitum. They were considered satiated when they stopped searching for feed and assembled in the corners of the aquaria.

Before stocking fish in the tanks after feeding with rotifers for 7 days, a sample of 30 larvae were measured for total length $(\mathrm{mm})$ using a ruler to the nearest $0.1 \mathrm{~mm}$ alongside checking the survival rates. Thereafter, a sample of 30 fish fry from each tank was measured for total length at 7-day intervals. Dead fish fry, if any, were collected and counted during the sampling time. At the termination of the experiment, the fish remaining in each tank were counted and a sample of 30-fish fry from each tank was measured for total length and their mortality rates were monitored and recorded. Data was analyzed using Statistica version 8.0 computerized program by subjecting them to one-way analysis of variance (ANOVA) at $P<0.05$ to obtain significant differences among the treatments for water quality parameters and treatments. Pearson's correlation was used to determine the relationship between water quality parameters and growth and survival of catfish fry and also between survival rate and total length. The specific growth rate (SGR) of the fry was calculated with formulae [6]:

$$
\mathrm{SGR}=100 *(\operatorname{LnTL}-\mathrm{LnTLo})^{-t},
$$

where SGR: specific growth rate $\left(\%^{- \text {day }}\right)$, Ln: natural logarithm, TL: final total length $(\mathrm{mm})$, TLo: initial total length $(\mathrm{mm})$, and $t$ : time (days) or feeding period.

\section{Results}

Water quality characteristics in the treatments A, B, and C during the 21-days experiment are summarized in Table 1. There was no significance difference $(P>0.05)$ in DO, temperature and TAN. Slight significant differences were experienced in nitrite-nitrogen and $\mathrm{pH}$ and among treatments A, B, and C at some individual sample dates. The mean DO concentration recorded in the morning and afternoon was more than $3.50 \mathrm{mg}^{-1}$ in all the treatments. Mean TAN was less than $0.62 \mathrm{mg}^{-1}$ (range of $0.24-0.62$ ) and nitritenitrogen less than $0.20 \mathrm{mg}^{-1}$ (range of $0.004-0.109$ ). The mean temperature in the morning $(9.00 \mathrm{AM})$ and afternoon (4.00 PM) ranged between $21.80^{\circ} \mathrm{C}-22.00^{\circ} \mathrm{C}$ and $24.00^{\circ} \mathrm{C}$ $25.00^{\circ} \mathrm{C}$, respectively. The lowest $\mathrm{pH}$ recorded in all the treatments was 6.93 and highest was 7.75. There was a decrease in TAN in all the treatments. However, there was no poor water quality conditions observed throughout the study.

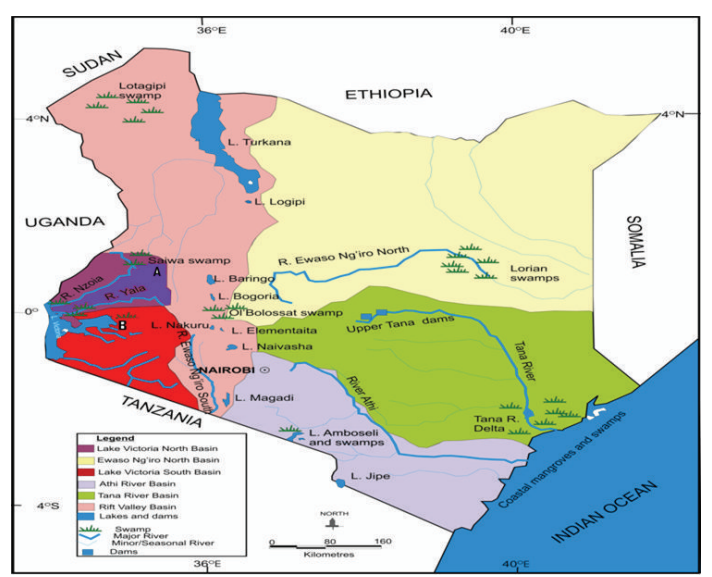

(a)

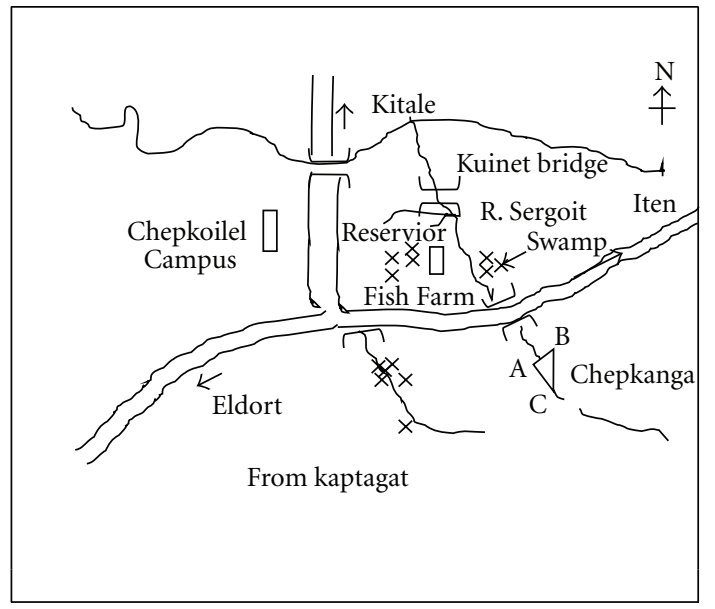

$$
\begin{aligned}
& \times \times \times \text { Papyrus swamp } \quad=\text { Roads } \\
& \sim \quad \text { Rivers }
\end{aligned}
$$

(b)

Figure 1: (a) Location of Chepkoilel Campus Station, Eldoret, Kenya indicated as region A near Saiwa Swamp. (b) The location of Chepkoilel Campus, Moi University, Kenya that holds the prominent Aquaculture Hatchery involved in experimental and commercial fish farming.

TABLE 1: Means \pm SD of water quality parameters observed at different treatments over 21 days period in a hatchery.

\begin{tabular}{lccc}
\hline Parameter & Treatment A & Treatment B & Treatment C \\
\hline DO $\left(\mathrm{mgL}^{-1}\right)$ & $4.37 \pm 0.57$ & $4.36 \pm 0.54$ & $4.41 \pm 0.56$ \\
Temp. ${ }^{\circ} \mathrm{C}$ & $23.30 \pm 3.27$ & $23.32 \pm 3.25$ & $23.29 \pm 3.28$ \\
pH & $7.40 \pm 0.02$ & $7.281 \pm 0.005$ & $7.41 \pm 0.08$ \\
TAN $\left(\mathrm{mgL}^{-1}\right)$ & $0.49 \pm 0.008$ & $0.44 \pm 0.004$ & $0.48 \pm 0.003$ \\
$\mathrm{NO}_{3}-\mathrm{N}\left(\mathrm{mgL}^{-1}\right)$ & $0.04 \pm 0.003$ & $0.039 \pm 0.004$ & $0.04 \pm 0.003$ \\
\hline
\end{tabular}

At the start of the experiment after 7 days of rotifer feeding before stocking in experimental tanks, the larvae had 


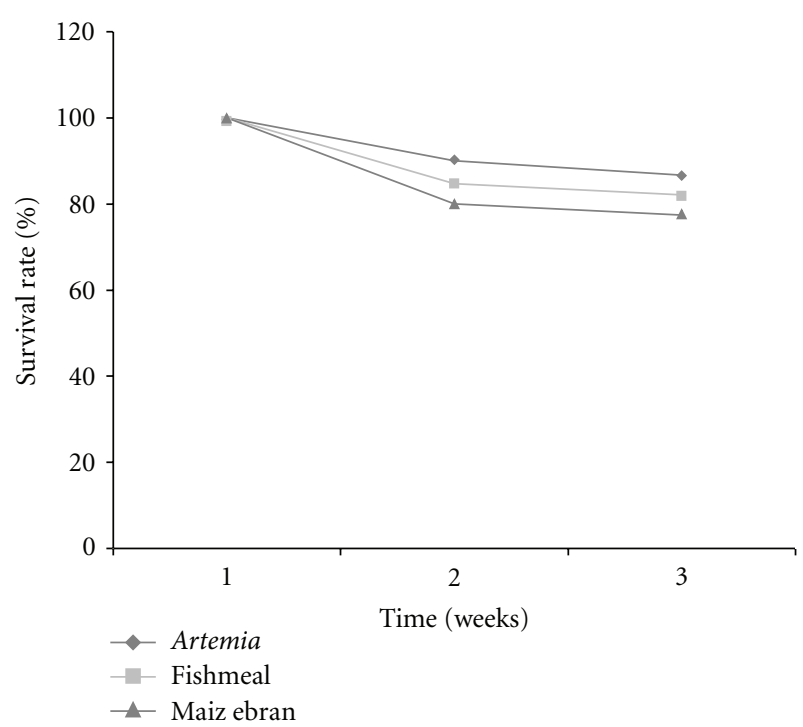

Figure 2: The cumulative survival rates (\%) of Clarias gariepinus larvae and fry fed on three different diets over a period of 14 days $($ Age $\pm S D)$.

an average uniform TL of $6.940 \pm 0.1829 \mathrm{~mm}$. Significant differences $(P<0.05)$ in fish growth in TL after stocking in glass tanks were found among treatments. A clear departure in growth in the experimental tanks in TL was observed after the 7th day in all the Treatments indicating significance differences between them $(P<0.05)$. The average TL at the end of the experiment was Treatment A (15.003 \pm $0.21 \mathrm{~mm})$, Treatment B $(12.96 \pm 0.17 \mathrm{~mm})$, and Treatment $\mathrm{C}(11.90 \pm 0.33 \mathrm{~mm})$. Pearson's correlation indicated no significant relationship $(r=0.10 ; P>0.05)$ between water quality parameters and the fish fry total length. Fry fed on Artemia nauplii (Treatment A) had the highest mean specific growth rate $\left(6.47 \%^{- \text {day }}\right)$ followed in decreasing order by those fed on fishmeal $\left(5.532 \%^{- \text {day }}\right)$ and maize bran $\left(4.960 \%^{- \text {day }}\right)$.

There was a weak correlation between water quality parameters and survival rates of the fish fry $(r=0.11 ; P>$ 0.05). Pearson's correlation exhibited a strong relationship between total length and survival rate $(r=0.85 ; P<0.02)$. Survival rate was relatively high for fish fed on Artemia nauplii unlike fish fed on fishmeal and maize bran which had significantly lower values $(P<0.05)$ at the end of the experiment (Figure 2). Nevertheless, there was significant difference $(P<0.05)$ in percent cumulative survival among the three Treatments. Percent cumulative survival decreased with time (in weeks) in all Treatments. After three weeks, $100 \%$ cumulative survival was reduced to: $\mathrm{A}=86.66 \pm$ $1.527 \%, \mathrm{~B}=82.00 \pm 1.00 \%$, and $\mathrm{C}=77.32 \pm 1.547 \%$.

\section{Discussion}

In this study, larvae and fry of Clarias gariepinus, readily consumed rotifers at the onset of feeding in the hatchling tank after yolk absorption up to the 7th day of feeding as evidenced by Nyina-Wamwiza et al. [8] who pointed out that at the onset of exogenous feeding, larvae of the African catfish are able to eat, digest, absorb, and metabolize nutrients since they have developed a sizeable mouth and digestive system. The distended intestinal tract of the fish and the marked satiation behavior evidenced at the onset of feeding. Therefore, there were no obvious nondietary effects on growth for rotifer feeds as starter feeds that gave an overall average growth of $6.940 \mathrm{~mm}$ as TL before other feeding types were introduced. This could be attributed to the food size of rotifers [9]. Significant differences were found among treatments in total length (TL) over the culture period. Fish growth for the remaining 14 days appears to have been influenced by the type of diet. Lack of significant differences in Pearson's correlation between fry growth and water quality parameters signify that water quality parameters might have not influence the final growth results. This study confirmed that live Artemia nauplii are a good feed for Clarias gariepinus larvae and fry if raised indoors.

The growth in TL of larvae and fry in this study was considered to be significantly lower than what has been reported in the literature. Verreth et al. [10] reared Clarias gariepinus larvae for 10 days on decapsulated Artemia cysts. They obtained a mean TL of $(15.954 \pm 1.021 \mathrm{~mm})$ after 10 days. Their results showed higher growth compared to results obtained in this study. They did however elevate the mean temperatures to $27.50^{\circ} \mathrm{C}$ in a recirculatory system (water flow $0.8 \mathrm{~L} / \mathrm{min}$ ) compared to average temperature of $24.33 \pm 0.957^{\circ} \mathrm{C}$ in this study. Hecht [5] confirmed that fish metabolic rate and subsequent growth are known to increase with rise in temperature and for optimal DO levels that were almost uniform in this study. At lower temperature a proportionally large part of the food, administered in high feeding levels is not consumed. Expressed as a percentage of all lipids, Artemia nauplii have an EPA content of 0.25 and DHA content of 2.7. Fishmeal contains an EPA of 0.04 and DHA content of 1.1 while maize bran has got an EPA of 0.01 and DHA 0.83 [11].

Using fishmeal, Nyina-Wamwiza et al. [6], recorded a SGR of $2.80 \pm 0.50 \mathrm{~cm}$ after a period of 61 days. These studies seem to be consistent with the range of protein digestibility values (75-95\%) reported for other freshwater fish fed with practical selected diets [12]. Diets that contain a high level of animal protein and those composed principally of plantbased ingredients are all highly digestible. Improvement of protein digestibility could be attributable to the reduction or elimination of different antinutrients during the pretreatment process, especially phytic acid and tannins which are known to interact with protein to form complexes. This can be also related to higher efficiency of the thermal treatment, reducing trypsin and chymotrypsin inhibitory activities [13].

However, fry fed on maize bran had a poor performance in growth and lagged behind than fry fed on other diets throughout the culture period. The poor performance can be attributed to several factors, mainly that larvae did not readily accept the maize bran and only about $10 \%$ reached satiation. Low palatability was therefore a possible cause for poor growth performance. Also, poor performance may have been caused by inadequate utilization of feed (maize bran) or digestion of the feed. There are indications that the digestive 
capacity of the prey organism is important for the digestion of the feed by the fish.

According to Pillay [14], enzymes of prey stimulate proteolytic activity in the fish larvae. Therefore, by comparing Artemia nauplii, fishmeal and maize bran, and the results seem to reflect a difference in feed ingestion more than in nutritional quality. The nutritional characteristics of Artemia nauplii with higher crude protein content of $74 \%$, differ from fishmeal (55\%) and maize bran (13.3\%) [15]. Artemia nauplii have $3 \%$ carbohydrates content with a lipid content of $18 \%$. Fishmeal has $30 \%$ carbohydrate with a lipid content of $6 \%$ compared to maize bran that has $70 \%$ carbohydrates and $4.5 \%$ lipid content. Therefore, the high crude protein content in Artemia nauplii (74\%) compared to fishmeal and maize bran (55\% and $13.3 \%$ resp.), may be responsible for the greater TL for the fish larvae and fry fed on Artemia nauplii.

A strong relationship between survival rate and TL could indicate that the more the fish survive, the more they grow which could only be informative if other factors such as environmental variables and husbandry requirements in the hatchery remain constant. On the other hand, the survival rates in this experiment for fish fed on Artemia nauplii were generally high, but slightly lower than what has recorded in literature; probably due to difference in husbandry techniques employed. When working with catfish fry in small earthen ponds, de Graaf and Janssen [16] had major mortalities that occurred during the early period of the nursing phase: which is the same phenomenon depicted in this study. Fish fed on fishmeal had a lower survival rate compared to Artemia nauplii, but a higher growth as compared to maize bran. The reduced survival probably could not be attributed to diet composition but could be as a result of starvation. This is because fish appeared emaciated and weak due to lack of food in their gut. It is therefore clear that maize bran is not suitable for rearing Clarias gariepinus larvae and fry. Nevertheless, cannibalism among Clarias gariepinus larvae, which is of two types, is primarily caused by differential growth of fish in a population and lack of feeds [6]. Fish measurements were fairly uniform within each treatment during each sampling and they were fed at 2-hour interval from $10 \mathrm{AM}$ to $6 \mathrm{PM}$ to satiation. Thus, no cannibalism was observed in the three treatments. Food availability however, has shown to have the greatest effect on the behavior of fish and hence on the rate of cannibalism. Cannibalism was highly expected in fish fed maize bran for they did not utilize the feed, but they were too weak to cannibalize. This agrees with Hecht [5], who found that weak fish were not able to continue cannibalizing.

The results of this research study demonstrate that Artemia nauplii and rotifers are suitable as first food for Clarias gariepinus larvae and fry for purpose of enhancing faster growth performance and survival. However, rotifers would be preferred as starter feeds due to the availability and cost implications of obtaining Artemia cysts in the developing nations. This research revealed that maize bran was unsuitable for first feeding Clarias gariepinus fry after the starter feed (rotifers). Fishmeal could probably be preferred than maize bran but of less consequence as compared to Artemia nauplii; although is less costly and available than Artemia cysts. Basing on the availability of enough funds, large-scale commercial fish farming practicing Clarias gariepinus larval culture and fingerling production is recommended that they raise their larvae probably on rotifers and Artemia nauplii as starter feeds for the first 7-10 days. However for small scale African catfish, farmers should probably raise their larvae and subsequent juveniles on rotifers as first feeds. If there are no funds to purchase Artemia cysts, fishmeal may be preferred. On the other hand, environmental conditions along with water parameters should be monitored and checked when breeding African catfish like other fish species for higher survival rates and higher growth performances. Water parameters to be monitored include TAN, $\mathrm{DO}, \mathrm{NO}_{3}-$ $\mathrm{N}, \mathrm{pH}$, and temperature among other parameters. Further research and incorporation of body mass could give more information on the relationship between TL and changes in body mass among treatments with time.

\section{Acknowledgment}

The Department of Fisheries, Moi University, Kenya provided funds, chemicals, apparatus, and other reagents that were necessary for the success of this project report.

\section{References}

[1] FAO, World Agriculture Towards 2015/2030, FAO, Rome, Italy, 2006.

[2] S. Y. Sulem, E. T. Tomedi, S. Mounchili, S. Tekeng, and R. E. Brummett, "Survival of Clarias gariepinus fry in earthen ponds: effects of composts and leaks," Aquaculture, vol. 260, no. 1-4, pp. 139-144, 2006.

[3] P. De Kimpe and J. C. Micha, Advances in Aquaculture, Cambridge University Press, New York, NY, USA, 1974.

[4] P. Ritcher, Composition of Feed for Clarias Gariepinus Bangui, Central African Republic, 1976.

[5] T. Hecht, "Consideration of African aquaculture," World Aquaculture1, vol. 31, pp. 12-19, 2000.

[6] L. Nyina-Wamwiza, B. Wathelet, J. Richir, X. Rollin, and P. Kestemont, "Partial or total replacement of fish meal by local agricultural by-products in diets of juvenile African catfish (Clarias gariepinus): growth performance, feed efficiency and digestibility," Aquaculture Nutrition, vol. 16, no. 3, pp. 237$247,2010$.

[7] C. C. Ngugi, J. Bowman, and B. Omolo, A New Guide to Fish Farming in Kenya, Aquaculture Collaborative Research Support Programme, Corvallis, Ore, USA, 2007.

[8] L. Nyina-Wamwiza, B. Wathelet, and P. Kestemont, "Potential of local agricultural by-products for the rearing of African catfish Clarias gariepinus in Rwanda: effects on growth, feed utilization and body composition," Aquaculture Research, vol. 38, no. 2, pp. 206-214, 2007.

[9] G. D. Treece, "Artemia production for marine larval fish culture," Southern Region Aquaculture Centre (SRAC), Production no. 702, 2000.

[10] J. Verreth, E. H. Eding, G. R. M. Rao, R. Huskens, and H. Segner, "A review of feeding practices, growth and nutritional physiology in larvae of the catfishes Clarias gariepinus and Clarias batrachus," Journal of the World Aquaculture Society, vol. 24, no. 2, pp. 135-144, 1993. 
[11] J. Sargent, L. McEvoy, A. Estevez et al., "Lipid nutrition of marine fish during early development: current status and future directions," Aquaculture, vol. 179, no. 1-4, pp. 217-229, 1999.

[12] K. Köprücü and Y. Özdemir, "Apparent digestibility of selected feed ingredients for Nile tilapia (Oreochromis niloticus)," Aquaculture, vol. 250, no. 1-2, pp. 308-316, 2005.

[13] R. Alonso, A. Aguirre, and F. Marzo, "Effects of extrusion and traditional processing methods on antinutrients and in vitro digestibility of protein and starch in faba and kidney beans," Food Chemistry, vol. 68, no. 2, pp. 159-165, 2000.

[14] T. V. R. Pillay, Aquaculture Principles and Practices, Cambridge University Press, New York, NY, USA, 1993.

[15] ADCP, "Aquaculture development and coordination programme, fish feeds and feeding in developing countries," Report on the ADCP Feed Development Programme, FAOADCP/REP/07/26, Rome, Italy, 1987.

[16] G. de Graaf and H. Janssen, "Artificial reproduction and pond rearing of the African catfish in Sub-Saharan Africa, A Handbook," FAO Fisheries Technical 362, 1996. 

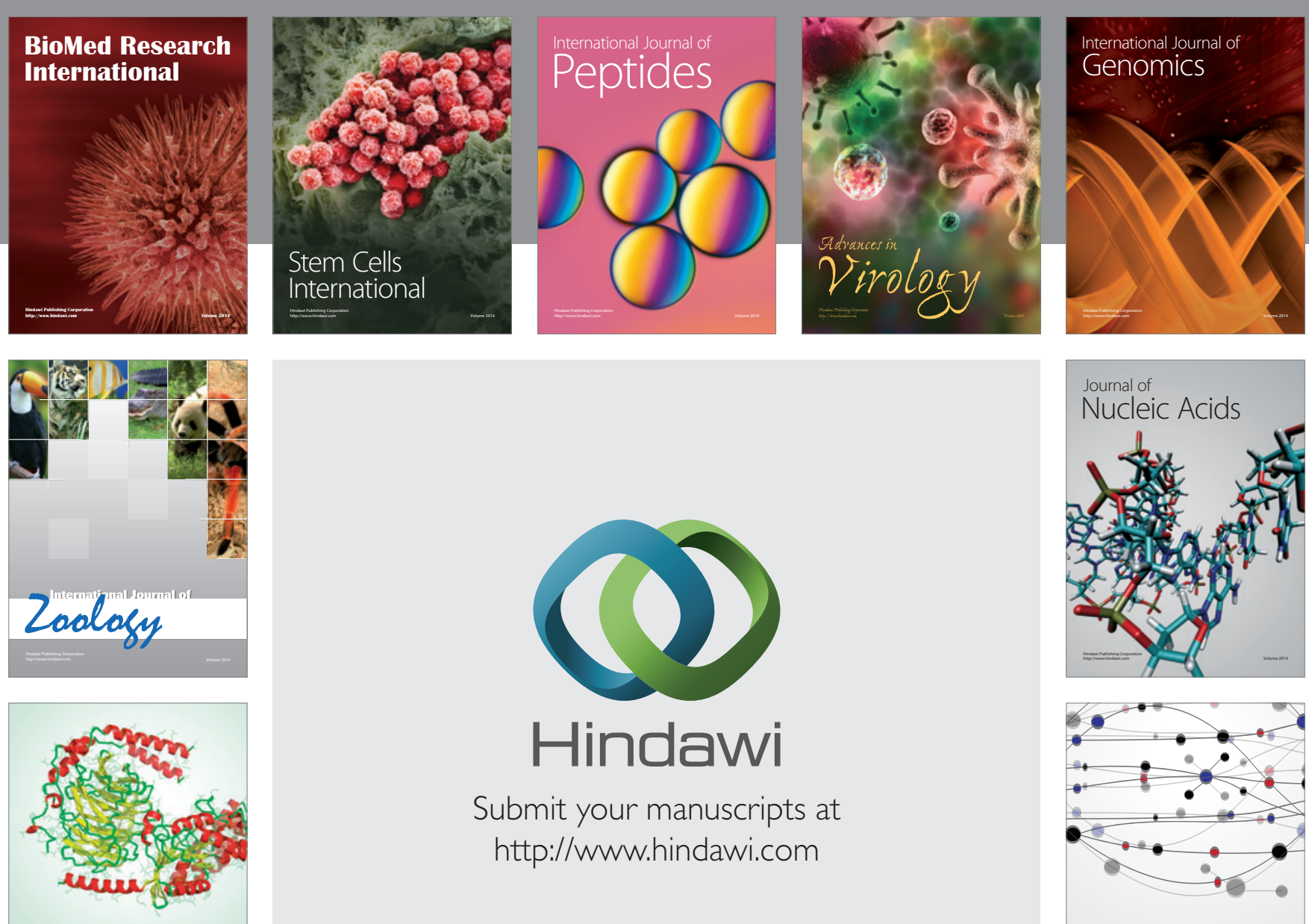

Submit your manuscripts at

http://www.hindawi.com

Signal ${ }^{\text {Jumal }}$ Transduction
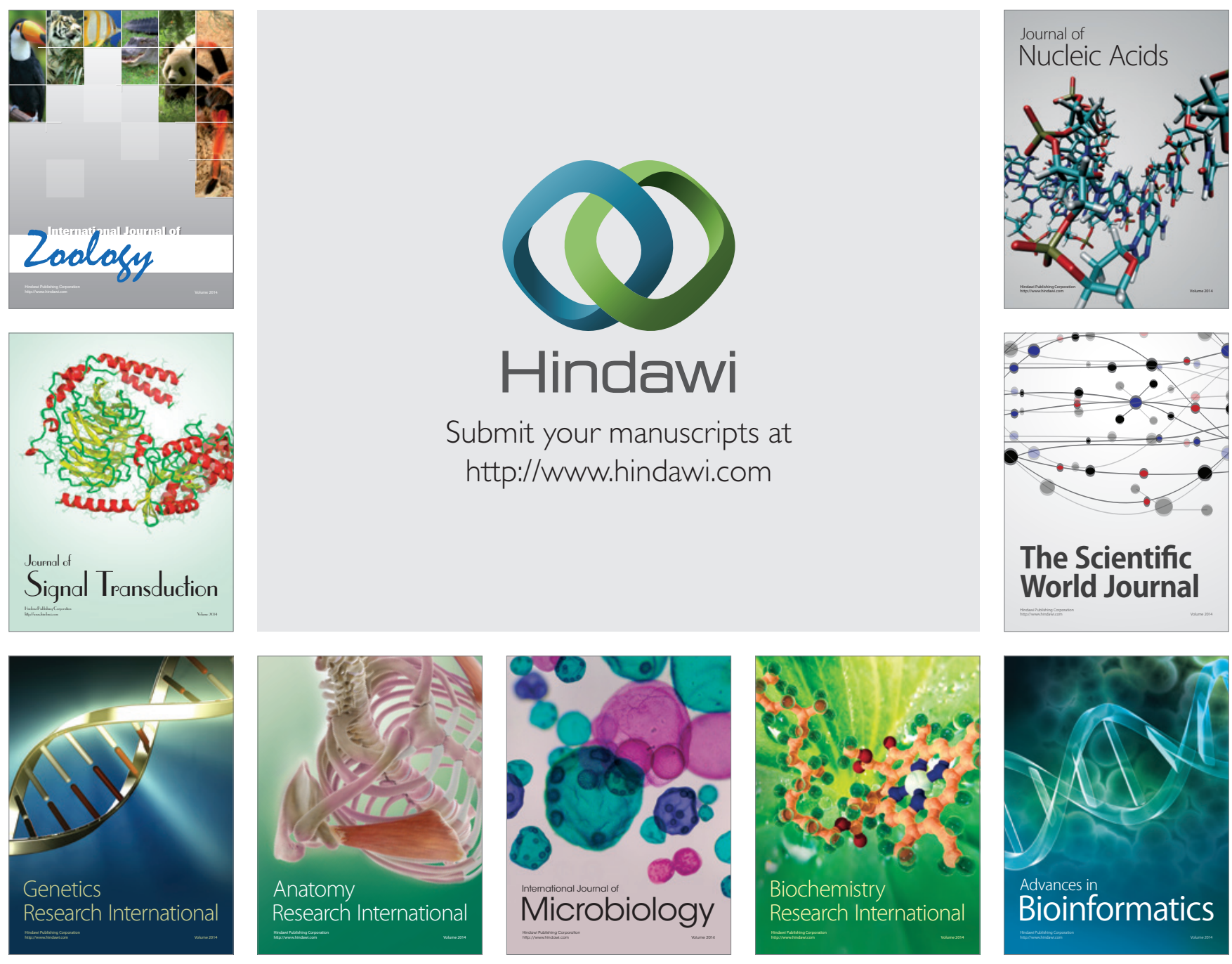

The Scientific World Journal
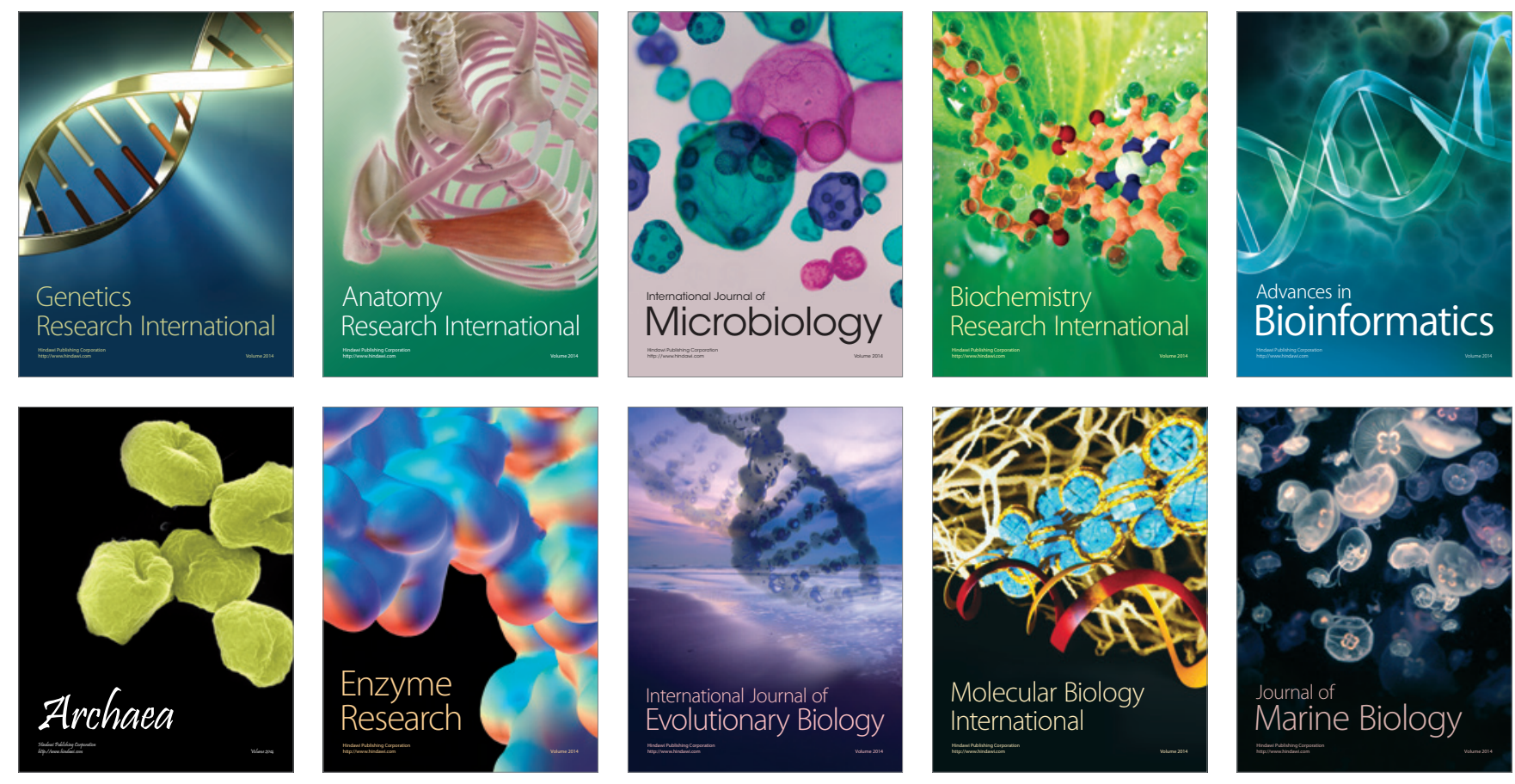